\title{
MPO-ANCA associated vasculitis with mononeuritis multiplex following influenza vaccination
}

\author{
Stefanie Eindhoven ${ }^{1,6^{*}} \mathbb{D}$, Jolien Levels ${ }^{1}$, Margriet Huisman ${ }^{2}$, Koos Ruizeveld de Winter ${ }^{3}$, Virgil Dalm ${ }^{4,5}$ \\ and Rehmat Alwani ${ }^{1}$
}

\begin{abstract}
Background: Although influenza vaccines are generally safe and effective, a variety of autoimmune phenomena have been reported after vaccination over the past years, such as Guillain-Barre syndrome, rheumatoid arthritis, pemphigus vulgaris, psoriasis, giant cell arteritis and anti-neutrophil cytoplasmic antibody (ANCA) associated vasculitis (AAV).

Case report: We describe the case of a 67-year old man who presented with a myeloperoxidase-ANCA associated vasculitis with renal involvement and mononeuritis multiplex after seasonal influenza vaccination. He was initially treated with intravenous cyclophosphamide and high-dose prednisolone followed by maintenance treatment consisting of azathioprine and prednisolone.

Conclusion: We hypothesize that seasonal influenza vaccination triggered a systemic immune response in a susceptible patient to develop AAV with renal involvement and vasculitic neuropathy. In general, seasonal influenza vaccinations are considered to be safe, however, clinicians should be aware of this rare phenomenon.
\end{abstract}

Keywords: Influenza vaccination, Anti-neutrophil cytoplasmic antibody (ANCA), Vasculitis

\section{Background}

Seasonal influenza vaccination is widely used in the western world, particularly in the elderly population, chronically ill patients, immunocompromised subjects and health care workers to provide protection against influenza and its potential secondary complications. Although influenza vaccines are generally safe and effective, a variety of autoimmune phenomena have been reported after vaccination over the past years, such as Guillain-Barre syndrome, rheumatoid arthritis, pemphigus vulgaris, psoriasis, Henoch-Schönlein purpura, polymyalgia rheumatic, giant cell arteritis and anti-neutrophil cytoplasmic antibody (ANCA) associated vasculitis (AAV) [1-5]. AAV is a rare disease with an overall annual incidence of $13-20$ cases per million individuals,

\footnotetext{
*Correspondence: s.eindhoven@gmail.com

${ }^{6}$ Department of Internal Medicine, Room F104, IJsselland Hospital,

P.O. Box 690, 2900 AR Capelle aan den IJssel, The Netherlands

Full list of author information is available at the end of the article
}

with a peak incidence of only 65 per million/year in those aged $65-74$ years $[6,7]$. AAV is a small to medium vessel vasculitis, and comprises three syndromes: granulomatosis with polyangiitis (GPA), microscopic polyangiitis (MPA) and eosinophilic granulomatosis with polyangiitis (EGPA) [8]. Here we describe a case of a patient presenting with AAV after influenza seasonal vaccination.

\section{Case report}

A 69-year-old Caucasian male patient, with no significant medical history, was evaluated in the IJsselland hospital. Since 8 weeks he had been suffering from fatigue, intermittent fever and night sweats, weight loss $(4 \mathrm{~kg})$ and macroscopic haematuria. In addition, he complained of progressive muscle weakness in hands and legs as well as stiffness, numbness and tingling of both hands. He had gradually lost the ability to walk due to a lack of strength in his legs. Clinical symptoms started 2 weeks after 
influenza vaccination. Over the past 3 years he received influenza vaccinations twice without any complications.

Physical examination revealed weakness in both his upper legs and arms and a reduced sense of feeling in his right arm. Also, both hands showed signs of muscular atrophy of the thumb muscles with flattening of the ball. The tendon reflexes at his legs were normal.

Blood tests showed raised levels of erythrocyte sedimentation rate (ESR) and C-reactive protein (CRP), a mild normocytic anaemia, leukocytosis and normal renal function (creatinine $87 \mu \mathrm{mol} / \mathrm{l}$ ) (Table 1). At admission the urinalysis demonstrated no active urinary sediment. Three weeks after hospital admission, serology revealed a positive perinuclear anti-neutrophil cytoplasmic antibody (pANCA) with positive myeloperoxidase (MPO)ANCA at a titer of $46 \mathrm{E} / \mathrm{ml}$ (reference $<3.5 \mathrm{E} / \mathrm{ml}$ ). It was unknown if the patient was MPO-ANCA positive in the past. Imaging studies with computed tomography scan (CT scan) of chest and abdomen, magnetic resonance imaging (MRI) of head and neck, and positron emission tomography with 2-deoxy-2[fluorine-18]fluoroD-glucose with computed tomography (18F-FDG PET/ CT) revealed no abnormalities. No increase in cell count was seen during lumbar puncture. Cultures of cerebrospinal fluid, blood and urine as well as a tuberculin skin test and a quantiferon test were negative. Electromyography (EMG) showed decreased compound muscle action potentials (cmap) of the peroneal nerves of both legs and the tibial nerve of the right leg. All the additional research was done before administration of prednisolone. During hospitalization kidney function deteriorated, with a maximum serum creatinine level of $178 \mu \mathrm{mol} / \mathrm{l}$ (upper limit of reference value $104 \mu \mathrm{mol} / \mathrm{l}$ ). Three weeks after hospital admission, the urinalysis became deviant with red blood cells $(2+)$ and protein $(2+)$, dysmorphic erythrocyes and/ or red cell casts were not observed. Renal biopsy was conducted which revealed a small and medium-size vasculitis and tubulo-interstitial infiltration (Figs. 1 and 2). Three out of ten glomeruli showed glomerulosclerosis. Additional immunofluorescence with IgA, IgG, IgM, C3 and $\mathrm{C} 1 \mathrm{q}$ were negative.

Our patient was diagnosed having MPO-ANCA associated vasculitis with involvement of kidneys and peripheral nerves one month after admission to the hospital. Initial symptoms started two weeks after seasonal influenza vaccination. Because of rapidly progressive disease therapy was initiated with high dosages of intravenously administered prednisolone (1000 $\mathrm{mg})$ for three consecutive days followed by oral prednisolone in tapering regimen, in combination with intravenous pulse cyclophosphamide (700 mg: $10 \mathrm{mg} / \mathrm{kg}$ adjusted for age and renal function) and trimethoprim/sulfamethoxazole (480 mg daily) for Pneumocystis jiroveci pneumonia
Table 1 Laboratory data of the patient on admission

\begin{tabular}{|c|c|c|}
\hline & & Reference value \\
\hline \multicolumn{3}{|l|}{ Hematology } \\
\hline Hemoglobin (mmol/l) & 7.6 & $8.5-11.0$ \\
\hline Mean corpuscular volume (fl) & 81 & $80-100$ \\
\hline Hematocrit (I/I) & 0.37 & $0.40-0.51$ \\
\hline Red blood cells & $4.7 \times 10 \mathrm{E} 12 / /$ & $4.6-6.1 \times 10 \mathrm{E} 12 / \mathrm{I}$ \\
\hline White blood cells & $20.6 \times 10 \mathrm{E} 9 / \mathrm{I}$ & $4.2-9.1 \times 10$ E9/I \\
\hline Neutrophils & $17.0 \times 10$ E9/I & $1.5-9.0 \times 10$ E9/I \\
\hline Lymphocytes (\%) & 7 & $20-50$ \\
\hline Monocytes (\%) & 9 & $2-10$ \\
\hline Eosinophils (\%) & 1 & $<5$ \\
\hline Basophils (\%) & 0 & $<2$ \\
\hline Platelets & $397 \times 10 \mathrm{E} 9 / \mathrm{I}$ & $165 \times 10$ E9/I \\
\hline \multicolumn{3}{|l|}{ Biochemistry/serology } \\
\hline Creatinine $(\mu \mathrm{mol} / \mathrm{l})$ & 87 & 59-104 \\
\hline Sodium (mmol/l) & 135 & $135-145$ \\
\hline Potassium (mmol/l) & 3.8 & $3.5-5.0$ \\
\hline Blood urea nitrogen (mmol/l) & 6.0 & $2.5-7.5$ \\
\hline C-reactive protein (mg/l) & 163 & $<5.0$ \\
\hline $\begin{array}{l}\text { Erythrocyte sedimentation rate } \\
(\mathrm{mm} / \mathrm{h})\end{array}$ & 103 & $<15$ \\
\hline Albumin (g/l) & 26 & $35-52$ \\
\hline Ferritin $(\mu \mathrm{g} / \mathrm{l})$ & 710 & $25-250$ \\
\hline Vitamin B12 (pmol/l) & 380 & $140-500$ \\
\hline Folic acid (nmol/l) & 10.3 & $10.4-42.4$ \\
\hline Total bilirubin $(\mu \mathrm{mol} / \mathrm{l})$ & 27 & $<21$ \\
\hline Gamma glutamyl transferase (E/I) & 240 & $<55$ \\
\hline Alkaline phosphatase (E/l) & 230 & $<115$ \\
\hline Aspartate aminotransaminase (E/l) & 28 & $<35$ \\
\hline Alanine aminotransaminase (E/l) & 34 & $<45$ \\
\hline Lactate dehydrogenasis (E/l) & 183 & $<248$ \\
\hline Creatine kinase (E/l) & 38 & $<171$ \\
\hline MPO-ANCA (E/ml) & 46 & $<3.5$ \\
\hline PR3-ANCA (E/ml) & 0.3 & $<7.0$ \\
\hline \multicolumn{3}{|l|}{ Urinary sediment } \\
\hline Protein & $2+$ & \\
\hline Hemoglobine & $2+$ & \\
\hline Red blood cells & 4-10/HPF & \\
\hline Dysmorphic red blood cells (\%) & $<40$ & \\
\hline
\end{tabular}

prophylaxis, according to the consensus regimen of the European vasculitis study group [9]. The cyclophosphamide treatment was continued for three months, resulting in remission of the disease process. Levels of ESR and CRP dropped and renal function stabilized (serum creatinine levels $140-150 \mu \mathrm{mol} / \mathrm{l})$. He was discharged from the hospital to a rehabilitation centre for further recovery. Patient continued on azathioprine for another 18 months. Remaining symptoms one year after initiation 


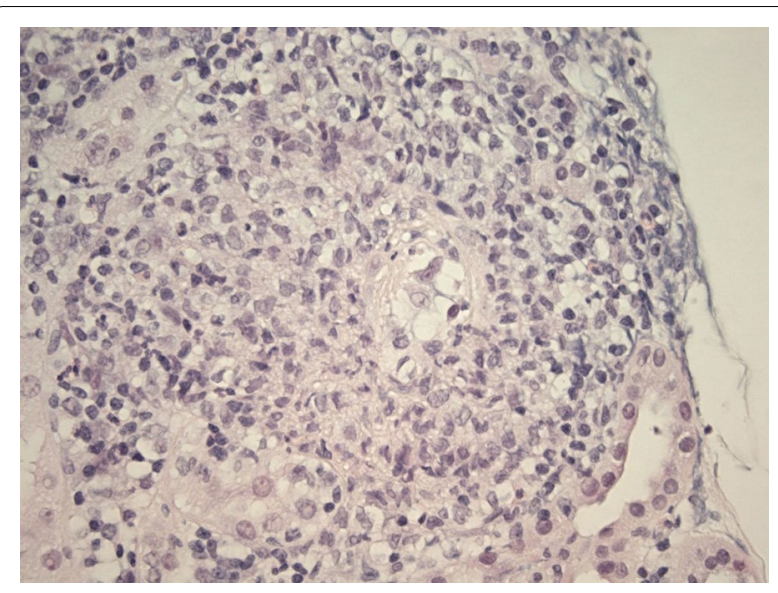

Fig. 1 Light microscopy imaging of the renal biopsy demonstrating a small vessel vasculitis. Original magnification $\times 400$, using Haematoxylin-eosin stain

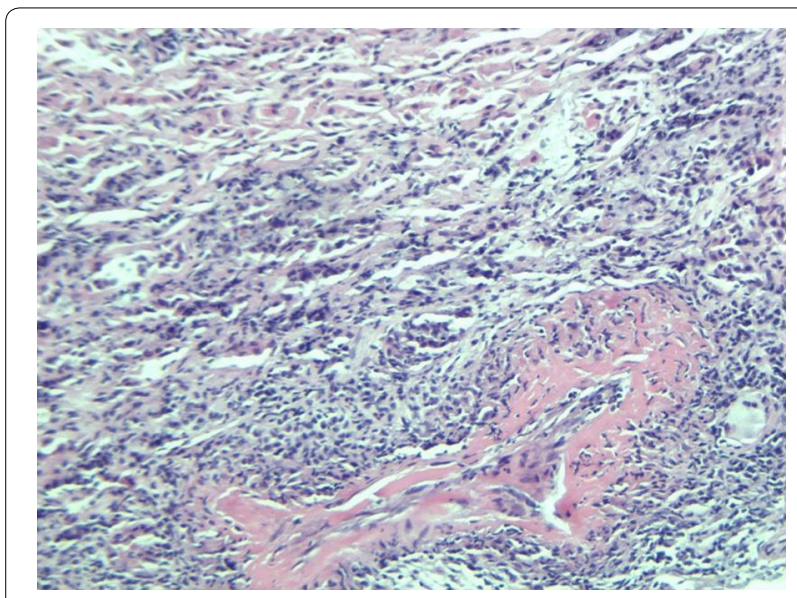

Fig. 2 Light microscopy imaging of the renal biopsy demonstrating a medium sized vasculitis. Original magnification $\times 100$, using Haematoxylin-eosin stain

of treatment consist of distal sensory loss of hands and feet and loss of fine motor skills of the hands.

\section{Discussion}

In this report, we described a patient with MPO-ANCA vasculitis with renal involvement and mononeuritis multiplex two weeks after seasonal influenza vaccination. Since the patient showed overlapping sets of clinical features it was difficult to diagnose the exact subtype of AAV $[10,11]$. Currently, a handful of AAV cases have been reported in temporal association with influenza vaccination [12-17]. Recently, The Brighton Collaboration Vasculitis Working Group published a systematic literature review on adverse events following immunization (AEFI) suggesting an association between influenza vaccination and vasculitis, however no evidence is found to confirm this association yet [18]. The temporal relationship with the influenza vaccine could have been completely coincidental in our case. Several other etiological factors, such as exposure to silica, viral or bacterial infections, medication and genetic susceptibility have also been correlated to AAV [19, 20].

Vasculitic neuropathy is characterized by a necrotizing vasculitis involving the small arterioles of peripheral nerves. Mononeuritis multiplex is a painful, asymmetrical, asynchronous sensory and motor peripheral neuropathy involving isolated damage to at least two separate nerve areas. It can be distributed bilaterally, distally and proximally throughout the body, as we describe in our patient [21]. Hadden et al. reported several case reports with vasculitic neuropathy after influenza vaccination [22]. Mononeuritis multiplex was not proven histopathologically in our patient. However, the progressive neurological impairment was highly suggestive of mononeuritis multiplex, especially in combination with the results of the performed EMG as well as the histopathological proven renal vasculitis (level 2 evidence according to The Brighton Collaboration Vasculitic Peripheral Neuropathy Working Group) [22].

The exact etiology of post-influenza vaccination vasculitis is unknown. Several possible underlying mechanisms have been postulated, such as molecular mimicry, autoimmune syndrome induced by adjuvants (ASIA) and viral ribonucleic acid (RNA). In molecular mimicry, a microbial/foreign antigen shares structural similarities with self-antigens. Prolonged inflammatory responses to these foreign antigens can therefore induce autoimmunity syndromes in predisposed individuals [23-25]. A second possible mechanism is ASIA. Adding an adjuvant to a vaccine antigen leads to several advantages, including dose sparing and the introduction of a more rapid, broader and strong immune response. However, disadvantages of these adjuvants have been described as well. The pathogenesis of the ASIA syndrome is founded on the hypothesis that an exposure to an adjuvant may trigger the development of an autoimmune disease [26, 27]. The influenza vaccination our patient received was the third vaccination in three years. The first two years he had no complications after the vaccination. In 2011, his first influenza vaccine contained 4 viral types: A/California/7/09 A (H1N1), A/Perth/16/2009 (H3N2), A/Victoria/2010/2009 and B/Brisbane/60/08. In 2012, his second influenza vaccine contained the same California type, but also contained B/Victoria/361/2011 (H3N2) and B/ Wisconsin/1/2010. His third vaccination consisted of the same California and Victoria types and of B/Massachussets/02/2012. Unfortunately, we were not able to obtain information on whether these vaccines were adjuvanted 
or not. According to the ASIA criteria defined by Alijotas-Reig, our patient met three major criteria, including exposure to an external stimulus, minimum latency time of days and muscle weakness [28]. Recently, another possible mechanism has been proposed regarding influenza vaccines containing viral RNA which may increase the production of Proteinase 3 (PR3-ANCA) and thus further contribute to the development of AAV following influenza vaccination [17].

Several clinical trials have investigated the relapse rate of AAV after influenza vaccination. Overall, influenza vaccination does not seem to increase the relapse rate in patients with pre-existent AAV in remission $[29,30]$. Furthermore, the disease free survival was lower in patients not vaccinated [30]. A recent report showed no changes in auto-antibody levels after influenza vaccination in a small group of healthy individuals [29]. However, one study found silent auto-antibody formation after influenza vaccination in healthy individuals, but this did not reach statistical significance and none of the participants had clinical symptoms of systemic autoimmune disease [31].

In this report we described another case suggesting a temporal relationship between influenza vaccination and AAV with mononeuritis multiplex. However, existing literature does not support a causative link between vaccination and vasculitis yet. Further research is needed to evaluate this potential causal relationship, especially given the extent of influenza vaccinations administered to the peak age incidence population on an annual basis. In general, seasonal influenza vaccinations are considered to be safe, however, clinicians should be aware of this rare phenomenon.

\begin{abstract}
Abbreviations
pANCA: perinuclear anti-neutrophil cytoplasmic antibody; ANCA: anti-neutrophil cytoplasmic antibody; AAV: ANCA-associated vasculitis; GPA: granulomatosis with polyangiitis; MPA: microscopic polyangiitis; EGPA: eosinophilic granulomatosis with polyangiitis; EMG: electromyography; cmap: compound muscle action potentials; ESR: erythrocyte sedimentation rate; CRP: C-reactive protein; MPO-ANCA: myeloperoxidase anti-neutrophil cytoplasmic antibody; PR3-ANCA: proteinase 3 anti-neutrophil cytoplasmic antibody; CT scan: computed tomography scan; MRI: magnetic resonance imaging; 18F-FDG PET/CT: positron emission tomography with 2-deoxy-2[fluorine-18]fluoro-D-glucose; ASIA: autoimmune syndrome induced by adjuvants; RNA: viral ribonucleic acid.
\end{abstract}

\section{Authors' contributions}

SE wrote the first draft of the manuscript and contributed to all revisions of the manuscript. RA, JL and MH diagnosed the patient with MPO-AAV and treated him subsequently. KR performed the histopathological examination of the kidney biopsy and thus contributed to the final diagnosis. VD was consulted during admission of the patient and contributed to the revision of the manuscript. RA supervised the findings of this work. All authors read and approved the final manuscript.

\section{Author details}

${ }^{1}$ Department of Internal Medicine, IJsselland Hospital, Capelle aan den IJssel, The Netherlands. ${ }^{2}$ Division of Rheumatology, Department of Internal Medicine, IJsselland Hospital, Capelle aan den IJssel, The Netherlands. ${ }^{3}$ Department of Pathology, Pathan, Rotterdam, The Netherlands. ${ }^{4}$ Division of Clinical Immunology, Department of Internal Medicine, Erasmus Medical Centre, Rotterdam, The Netherlands. ${ }^{5}$ Department of Immunology, Erasmus Medical Centre, Rotterdam, The Netherlands. ${ }^{6}$ Department of Internal Medicine, Room F104, IJsselland Hospital, P.O. Box 690, 2900 AR Capelle aan den IJssel, The Netherlands.

\section{Acknowledgements}

Not applicable.

Competing interests

The authors declare that they have no competing interests.

\section{Availability of data and materials}

Data sharing is not applicable to this article as no datasets were generated or analysed during the current study.

Consent for publication

We will provide a consent form for publication.

Ethics approval and consent to participate

Not applicable.

\section{Funding}

Not applicable.

\section{Publisher's Note}

Springer Nature remains neutral with regard to jurisdictional claims in published maps and institutional affiliations.

Received: 10 March 2017 Accepted: 6 November 2017

Published online: 13 December 2017

\section{References}

1. Gunes AT, Fetil E, Akarsu S, Ozbagcivan O, Babayeva L. Possible triggering effect of influenza vaccination on psoriasis. J Immunol Res. 2015:2015:258430.

2. Schattner A. Consequence or coincidence?: the occurrence, pathogenesis and significance of autoimmune manifestations after viral vaccines. Vaccine. 2005:23:3876-86.

3. Chen RT, Pless R, Destefano F. Epidemiology of autoimmune reactions induced by vaccination. J Autoimmun. 2001;16:309-18.

4. Soriano A, Verrecchia E, Marinaro A, Giovinale M, Fonnesu C, Landolfi R, Manna R. Giant cell arteritis and polymyalgia rheumatica after influenza vaccination: report of 10 cases and review of the literature. Lupus. 2012:21:153-7.

5. Felicetti P, Trotta F, Bonetto C, Santuccio C, Brauchli Pernus Y, Burgner D, Chandler R, Girolomoni G, Hadden RD, Kochhar S, Kucuku M, Monaco G, Ozen S, Pahud B, Phuong L, Bachtiar NS, Teeba A, Top K, Varricchio F, Wise RP, Zanoni G, Zivkovic S, Bonhoeffer J, Brighton Collaboration Vasculitis Working G. Spontaneous reports of vasculitis as an adverse event following immunization: a descriptive analysis across three international databases. Vaccine. 2016;34:6634-40.

6. Watts RA, Mahr A, Mohammad AJ, Gatenby P, Basu N, Flores-Suarez LF. Classification, epidemiology and clinical subgrouping of antineutrophil cytoplasmic antibody (ANCA)-associated vasculitis. Nephrol Dial Transplant. 2015;30(Suppl 1):i14-22.

7. Scott DG, Watts RA. Epidemiology and clinical features of systemic vasculitis. Clin Exp Nephrol. 2013;17:607-10.

8. Jennette JC, Falk RJ, Bacon PA, Basu N, Cid MC, Ferrario F, Flores-Suarez LF, Gross WL, Guillevin L, Hagen EC, Hoffman GS, Jayne DR, Kallenberg CG, Lamprecht P, Langford CA, Luqmani RA, Mahr AD, Matteson EL, Merkel PA, Ozen S, Pusey CD, Rasmussen N, Rees AJ, Scott DG, Specks U, Stone JH, Takahashi K, Watts RA. 2012 revised international Chapel Hill consensus conference nomenclature of vasculitides. Arthritis Rheum. 2013;65:1-11.

9. Jayne DR, Rasmussen N. Treatment of antineutrophil cytoplasm autoantibody-associated systemic vasculitis: initiatives of the European 
Community Systemic Vasculitis Clinical Trials Study Group. Mayo Clin Proc. 1997;72:737-47.

10. Hilhorst M, van Paassen P, Tervaert JW, Limburg Renal R. Proteinase 3-ANCA vasculitis versus myeloperoxidase-ANCA vasculitis. J Am Soc Nephrol. 2015;26:2314-27.

11. Tervaert JW, Limburg PC, Elema JD, Huitema MG, Horst G, The TH, Kallenberg CG. Detection of autoantibodies against myeloid lysosomal enzymes: a useful adjunct to classification of patients with biopsy-proven necrotizing arteritis. Am J Med. 1991;91:59-66.

12. Duggal T, Segal P, Shah M, Carter-Monroe N, Manoharan P, Geetha D. Antineutrophil cytoplasmic antibody vasculitis associated with influenza vaccination. Am J Nephrol. 2013;38:174-8.

13. Uji M, Matsushita H, Iwata S. Microscopic polyangiitis after influenza vaccination. Intern Med. 2005;44:892-6.

14. Birck R, Kaelsch I, Schnuelle P, Flores-Suarez LF, Nowack R. ANCA-associated vasculitis following influenza vaccination: causal association or mere coincidence? J Clin Rheumatol. 2009;15:289-91.

15. Spaetgens B, van Paassen P, Tervaert JW. Influenza vaccination in ANCAassociated vasculitis. Nephrol Dial Transplant. 2009;24:3258 (author reply 9).

16. Wharton CF, Pietroni R. Letter: polyarteritis after influenza vaccination. $\mathrm{Br}$ Med J. 1974;2:331-2.

17. Jeffs LS, Nitschke J, Tervaert JW, Peh CA, Hurtado PR. Viral RNA in the influenza vaccine may have contributed to the development of ANCAassociated vasculitis in a patient following immunisation. Clin Rheumatol. 2016:35:943-51.

18. Bonetto C, Trotta F, Felicetti P, Alarcon GS, Santuccio C, Bachtiar NS, Brauchli Pernus Y, Chandler R, Girolomoni G, Hadden RD, Kucuku M, Ozen S, Pahud B, Top K, Varricchio F, Wise RP, Zanoni G, Zivkovic S, Bonhoeffer J, Brighton Collaboration Vasculitis Working G. Vasculitis as an adverse event following immunization — systematic literature review. Vaccine. 2016;34:6641-51.

19. de Lind van Wijngaarden RA, van Rijn L, Hagen EC, Watts RA, Gregorini G, Tervaert JW, Mahr AD, Niles JL, de Heer E, Bruijn JA, Bajema IM. Hypotheses on the etiology of antineutrophil cytoplasmic autoantibody associated vasculitis: the cause is hidden, but the result is known. Clin J Am Soc Nephrol. 2008;3:237-52.
20. Scott DG, Watts RA. Systemic vasculitis: epidemiology, classification and environmental factors. Ann Rheum Dis. 2000;59:161-3.

21. Pagnoux C, Guillevin L. Peripheral neuropathy in systemic vasculitides. Curr Opin Rheumatol. 2005;17:41-8.

22. Hadden RDM, Collins MP, Zivkovic SA, Hsieh ST, Bonetto C, Felicetti P, Marchione P, Santuccio C, Bonhoeffer J, Brighton Collaboration Vasculitic Peripheral Neuropathy Working G. Vasculitic peripheral neuropathy: case definition and guidelines for collection, analysis, and presentation of immunisation safety data. Vaccine. 2017;35:1567-78.

23. Wraith DC, Goldman M, Lambert PH. Vaccination and autoimmune disease: What is the evidence? Lancet. 2003;362:1659-66.

24. Salemi S, D'Amelio R. Could autoimmunity be induced by vaccination? Int Rev Immunol. 2010;29:247-69.

25. Cusick MF, Libbey JE, Fujinami RS. Molecular mimicry as a mechanism of autoimmune disease. Clin Rev Allergy Immunol. 2012;42:102-11.

26. Pellegrino P, Clementi E, Radice $S$. On vaccine's adjuvants and autoimmunity: current evidence and future perspectives. Autoimmun Rev. 2015;14:880-8

27. Shoenfeld Y, Agmon-Levin N. 'ASIA'—autoimmune/inflammatory syndrome induced by adjuvants. J Autoimmun. 2011;36:4-8.

28. Alijotas-Reig J. Human adjuvant-related syndrome or autoimmune/ inflammatory syndrome induced by adjuvants. Where have we come from? Where are we going? A proposal for new diagnostic criteria. Lupus. 2015;24:1012-8.

29. Jeffs LS, Peh CA, Jose MD, Lange K, Hurtado PR. Randomized trial investigating the safety and efficacy of influenza vaccination in patients with antineutrophil cytoplasmic antibody-associated vasculitis. Nephrology (Carlton). 2015;20:343-51.

30. Stassen PM, Sanders JS, Kallenberg CG, Stegeman CA. Influenza vaccination does not result in an increase in relapses in patients with ANCAassociated vasculitis. Nephrol Dial Transplant. 2008;23:654-8.

31. Toplak N, Kveder T, Trampus-Bakija A, Subelj V, Cucnik S, Avcin T. Autoimmune response following annual influenza vaccination in 92 apparently healthy adults. Autoimmun Rev. 2008:8:134-8.

\section{Submit your next manuscript to BioMed Central and we will help you at every step:}

- We accept pre-submission inquiries

- Our selector tool helps you to find the most relevant journal

- We provide round the clock customer support

- Convenient online submission

- Thorough peer review

- Inclusion in PubMed and all major indexing services

- Maximum visibility for your research

Submit your manuscript at www.biomedcentral.com/submit
() Biomed Central 